\title{
ANALISIS PELAKSANAAN PROGRAM KELUARGA HARAPAN (PKH) DI DESA KOTA RANTANG KECAMATAN HAMPARAN PERAK
}

\author{
Siswati Saragi ${ }^{1}$, Maria Ulfa Batoebara ${ }^{2}$, Nur Ambia Arma ${ }^{3}$ \\ FISIP Universitas Dharmawangsa Medan \\ ambiaarma@dharmawangsa.ac.id
}

\begin{abstract}
ABSTRAK
Tujuan penelitian ini adalah untuk mengidentifikasi pelaksanaan penyaluran dana program keluarga harapan dimulai dari penetapan sasaran peserta hingga kendala yang terjadi dalam pelaksanaannya. Metode penelitian ini adalah kualitatif deskriptif dan teknik analisis Miles, Huberman dan Saldana, penelitian ini akan mendeskripsikan tahapan penetapan peserta yang dinyatakan layak miskin dan juga kendala dalam pelaksanaannya. Kemiskinan masih menjadi masalah penting bagi Negara Indonesia sehingga menjadi tanggung jawab pemerintah dalam rangka kesejahteraan masyarakat. Oleh karena itu pemerintah Indonesia harus mengalokasikan banyak pengeluaran untuk program-program dan kegiatan penanggulangan kemiskinan tersebut. Salah satu program yang telah dilakukan pemerintah Indonesia adalah program keluarga harapan (PKH). PKH merupakan program bersyarat yang sasaran program ini untuk peningkatan kesejahteraan masyarakat di bidang kesehatan dan pendidikan. Desa Kota Rantang merupakan salah satu desa di Indonesia yang mendapatkan bantuan program PKH. Hasil penelitian mengungkapkan bahwa penetapan peserta PKH dilakukan berdasarkan data yang sudah ada di sistem Data Terpadu Kesejahteraan Sosial (DTKS), namun tetap dilakukan pengecekan kebenaran kondisi peserta hingga diverifikasi ulang oleh Kementerian sosial. Sedangkan kendala yang terdapat dalam pelaksanaan yaitu masih sulitnya mengumpulkan semua peserta secara bersama-sama setiap bulan untuk pengecekan dan pembinaan.
\end{abstract}

Kata Kunci: Kemiskinan, Analisis Pelaksanaan, Program Keluarga Harapan,

\section{ABSTRACT}

The purpose of this research is to identify the implementation of the distribution of funds for the family hope program. Research metode is descriptive qualitative and the analysis techniques of Miles, Huberman and Saldana, this study will describe the stages of determining the participants who are declared deserving of poverty and also the obstacles in their implementation. Poverty is an important problem for Indonesia until now, so that it is the government's responsibility in the context of community welfare. Therefore, the Indonesian government must allocate a lot of expenditure for these poverty reduction programs and activities. One of the programs that have been carried out by the Indonesian government is the Family Hope Program (PKH). PKH is a conditional program whose target is to improve public welfare in the health and education sectors. Kota Rantang Village is one of the villages in Indonesia that has received PKH program assistance. The results of the study revealed that the determination of PKH participants was 
based on existing data in the Integrated Social Welfare Data System (DTKS), but it was still carried out to check the truth of the participant's condition until it was re-verified by the Ministry of Social Affairs. Meanwhile, the obstacles in the implementation are still difficult to gather all the participants together every month for checking and coaching.

\section{Keywords: Poverty; Implementation Analysis; Family Hope Program}

\section{PENDAHULUAN}

Indonesia merupakan Negara berkembang yang memiliki masalah kemiskinan hingga saat ini. Masalah kemiskinan di Indoensia semakin besar ketika terjadinya gejolak perekonomian yang disebabkan oleh gejolak nilai tukar rupiah terhadap mata uang asing, sehingga berdampak munculnya krisis ekonomi terparah di tahun 1998 dengan rata-rata pertumbuhan ekonomi turun dari 7 persen menjadi 13 persen (Bappenas, 2003). Sejak krisi itu, Indonesia dilanda masalah kemiskinan terparah sepanjang kehidupan. Meskipun hingga tahun 2019 telah mengalami perubahan yang sangat signifikan terhadap angka kemiskinan, namun masih menjadi masalah utama Indonesia terutama dalam pembangunan.

Jumlah penduduk miskin di Indonesia pada tahun 1996 sebanyak 22,5 juta jiwa. Sedangkan di tahun 1998 pasca krisis ekonomi menjadikan jumlah penduduk miskin sebanyak 49,5 juta jiwa (BPS, 2015). Namun jumlah penduduk miskin saat ini sudah mengalami penurunan yang signifikan. Berdasarkan catatan dari Badan Pusat Statistik (2019), jumlah penduduk miskin di Indonesia tahun 2018 sebanyak 25,67 juta jiwa dan tahun 2019 mengalami penurunan kembali sebesar 0,44\% menjadi 24,79 juta jiwa. Namun terjadi kenaikan jumlah penduduk miskin lagi di tahun 2020 akibat adanya pandemi covid-19. Jumlah penduduk miskin di Indonesia tahun 2020 adalah sebanyak 26,42 juta jiwa atau presentase sebesar 9,78\% (BPS, 2020). Trend kemiskinan yang fluktuatif tersebut masih menunjukkan angka kemiskinan yang besar di Indonesia sehingga masih menjadi fokus utama pemerintah khususnya dalam rangka pembangunan Indonesia.

Kemiskinan yang merupakan penghambat pembangunan ditandai dengan adanya keterbatasan, tidak memiliki kemampuan dan juga memiliki banyak kekurangan. Keterbatasan misalnya dalam mendapatkan kebebasan hidup sesuai tingkat harapan hidup, ketidakmampuan dalam mendapatkan pendidikan, mendapatkan akses kesehatan yang memadai serta mengalami kekurangan dalam pemenuhan kebutuhan dasar baik sandang maupun pangan (Lestari, 2008). Keterbatasan dan ketidakmampuan masyarakat dalam memenuhi kebutuhan dasar hidupnya umumnya disebabkan terbatasnya peluang usaha dan kesempatan kerja yang dimiliki, kurangnya keterampilan dan pengetahuan serta kurangnya perlindungan kerja yang layak.

Masyarakat miskin menjadi topik yang sangat penting sehingga perlu perhatian khusus pemerintah dalam penanggulangannya. Hal ini dikarenakan salah satu tujuan 
PUBLIK: Jurnal Manajemen Sumber Daya Manusia, Adminsitrasi dan Pelayanan Publik Sekolah Tinggi Ilmu Administrasi Bina Taruna Gorontalo Volume VIII Nomor 1, 2021

daripada pembangunan adalah menciptakan kesejahteraan bagi masyarakat Indonesia sebagaimana hasil deklarasi The sustainable Development Goals (SDG's) tahun 2015 atas keberlanjutan dari deklarasi The Mikkenium Development Goals (MDG's) tahun 2000 tingkat dunia. Sehingga untuk mencapai tujuan tersebut, pemerintah Indonesia perlu mengalokasikan pengeluaran untuk membiayai berbagai program dan kegiatan pembangunan setiap tahunnya (Birowo, 2011).

Berbagai alokasi anggaran telah dilakukan pemerintah Indonesia untuk programprorgam dan kegiatan yang bertujuan menurunkan angka kemiskinan. Tidak hanya berfokus pada bantuan masyarakat miskin, pemerintah juga melakukan analisis penyebab terjadinya kemiskinan dan menyelesaikan permasalahan. Salah satunya yang langsung berhubungan dengan kemiskinan adalah program yang dikenal sebagai program keluarga harapan $(\mathrm{PKH})$. Program perlindungan sosial ini dikenal dengan sebutan Conditional Cash Transfers (CCT) di dunia (Larasati, Muda, Batubara, \& Suharyanto, 2019; Suharyanto, 2015). Program ini merupakan bentuk perlindungan sosial dan kesejahteraan sosial yang dilaksanakan oleh Kementerian Sosial. Bentuk program ini adalah memberikan bantuan kepada masyarakat miskin agar mereka mendapatkan kebutuhan dasar seperti pendidikan dan kesehatan (Dulkiah, Sari, \& Irwandi, 2018; Kemensos, 2020).

Program $\mathrm{PKH}$ merupakan program bantuan sosial bersyarat. Artinya setiap masyarakat yang menjadi peserta sasaran program memiliki kewajiban yang ditentukan Kementerian Sosial sebagai syarat penerima bantuan. Tujuan program ini selain untuk menurunkan angka kemiskinan, juga untuk membuka akses bagi ibu hamil dan balita, lansia serta disabilitas mendapatkan manfaat layanan dan fasilitas kesehatan. Bagi anak usia sekolah mendapatkan manfaat pelayanan pendidikan. Dengan bantuan ini, tidak ada alasan bagi setiap masyarakat Indonesia tidak mendapatkan fasilitas kesehatan maupun pendidikan.

PKH selalu diupayakan untuk terus meningkatkan jumlah penerima manfaat setiap tahun seak pertama diluncurkan pada tahun 2007. Hingga tahun 2019 usia pkh menginjak 12 tahun, jumlah penerima PKH sebanyak 9.841.270 keluarga. Hal ini meningkat tajam dibanding pada tahun 2007 yakni hanya sebanyak 387.947 keluarga. Dengan merawat ibu hamil, balita dan meningkatkan nutrisi mereka, kemudian mengantarkan anak-anak ke bangku pendidikan, diharapkan akan berdampak jangka panjang terhadap pemutusan rantai kemiskinan lintas generasi (Ekardo, Firdaus, \& Elfemi, 2014).

Salah satu desa yang mendapatkan alokasi dana bantuan keluaga harapan tersebut adalah desa Kota Rantang Kecamatan Hamparan Perak. Penduduk desa Kota Rantang berjumlah 1.800 keluarag (KK), dimana sebanyak $1.789 \mathrm{KK}$ mendapatkan bantuan keluarga miskin dari pemerintah. Dari beberapa bantuan pemerintah tersebut, sebanyak 
404 KK mendapatkan bantuan PKH. program PKH di desa ini sudah ada sejak tahun 2015 dengan jumlah KK sebelumnya adalah sekitar 580 KK. Namun karena terjadinya KK yang mendapatkan bantuan lebih dari satu jenis bantuan pemerintah, maka pada tahun 2020 jumlah KK yang menerima PKH menjadi 404. Keluarga harapan ini ditujukan kepada masyarakat miskin dengan kriteria ibu hamil, ibu menyusui, balita dan anak sekolah dari tingkat dasar sampai tingkat atas, kemudian untuk lansia serta masyarakat penyandang disabilitas. Akan tetapi yang menjadi perhatian adalah dari total penduduk sebanyak $1.800 \mathrm{KK}$, sebanyak 1789 KK mendapatkan bantuan subsidi pemerintah salah satunya adalah PKH. Padahal yang terlihat selama pengamatan pra penelitian adalah banyak para peserta $\mathrm{PKH}$ yang dianggap dalam kondisi tidak miskin jika dilihat berdasarkan kriteria rumah peserta penerima manfaat.

Peneliti melihat di desa tersebut rata-rata rumah penduduknya sudah berdinding dan berlantaikan keramik. Selain itu, juga kondisi anak sekolah semuanya dapat sekolah bahkan ada yang sampai ke perguruan tinggi. Memiliki kendaraan dalm kondisi baik dan lain sebagainya. hal ini mengindikasikan bahwa penduduk tersebut sebagian besar adalah masyarakat miskin. Selain itu, PKH yang telah berjalan selama kurnag lebih 5 tahun seharusnya telah membantu masyarakat untuk keluar dari kategori miskin, pada kenyataannya masih banyak KK yang mendapatkan bantuan ini. Hal ini menyebabkan ketertarikan peneliti dalam melakukan penelitian lebih lanjut mengenai pelaksanaan penyaluran dana PKH khususnya identifikasi terhadap kriteria miskin yang memenuhi syarat peserta $\mathrm{PKH}$ semestinya. Tujuan penelitian ini adalah untuk mengetahui bagaimana proses pelaksanaan program keluarga harapan di desa Kota Rantang Kecamatan Hamparan Perak berawal dari penetapan peserta PKH, tahapan pencairan bantuan $\mathrm{PKH}$, dan untuk mengidentifikasi kendala-kendala yang ditemukan dalam proses pelaksanaan PKH tersebut. Oleh sebab itu, penelitian ini berfokus kepada proses penetapan peserta $\mathrm{PKH}$, proses pelaksanaan $\mathrm{PKH}$ serta kendala-kendala yang dihadapi dalam pelaksanaan $\mathrm{PKH}$.

\section{METODE PENELITIAN}

Penelitian ini dilakukan di Desa Kota Rantang Kecamatan Hamparan Perak, Kabupaten Deli Serdang. Adapun pertimbangannya awal penetapan lokasi adalah karena penulis merasa penyaluran dana $\mathrm{PKH}$ tidak tepat melihat kondisi rumah masyarakat Desa Kota Rantang yang jauh dari kata tidak layak. Penelitian ini menggunakan pendekatan kualitatif deskriptif. (Iskandar, 2009) menyatakan bahwa pendekatan penelitian kualitatif merupakan proses penelitian dan pemahaman yang berdasarkan pada metode yang menyelidiki suatu fenomena sosial dan masalah manusia, dengan cara menggambarkan secara kompleks, meneliti kata-kata, laporan terinci dari pandangan responden dan melakkan studi pada situasi yang alami. (Lexy J. Moleong, 2000) juga memberikan penjelasan bahwa penelitian kualitatif berarti 
prosedur penelitian yang menghasilkan data deskriptif berupa kata-kata tertulis atau lisan dari orang-orang yang diamati. Dalam hal ini, penelitian ini akhirnya akan mendeskripsikan terkait proses pelaksanaan Program Keluarga Harapan.

Teknik pengumpulan data yang digunakan adalah wawancara dan observasi. Target wawancara pada penelitian ini adalah, perangkat desa, pendamping desa dan juga masyarakat sebagai peserta PKH. Sedangkan teknik analisa data yang digunakan dalam penelitian ini adalah analisis kualitatif berdasarkan teori (Miles, Huberman, \& Saldana, 2014), yang terdiri atas 4 tahap yaitu: a. Pengumpulan data-data yang diperoleh dari teknik wawancara, observasi dan dokumentasi; b. Kondensasi data atau pemilihan, penyerdehanaan dan transfromasi data mentah yang telah di kumpulkan sebelumnya dan kemudian dituangkan dalam bentuk uraian atau laporan terstruktur dan rinci. Selanjutnya dirangkum dan dipilih pokok-pokok yang sesuai dengan fokus penelitian; c. Penyajian data yang merupakan pemaparan informasi yang disusun sebelumnya; serta d. Penarikan kesimpulan.

\section{HASIL PENELITIAN}

\section{Penetapan Sasaran Program Keluarga Harapan}

Program keluarga harapan merupakan salah satu program pemberian bantuan sosial kepada keluarga miskin dan rentan oleh Kementerian Sosial Republik Indonesia dengan berbagai syarat. Program ini dilakukan dengan tujuan percepatan penanggulangan kemiskinan. Secara internasional pemberian bantuan kepada masyarakat miskin seperti ini disebut dengan istilah Conditional Cash Transfers (CCT). Artinya bantuan ini berbentuk pemberian sejumlah uang secara tunai dari pemerintah pusat untuk setiap masyarakat miskin. Adapun beberapa sasaran program keluarga harapan ini terdiri atas 3 aspek yaitu pertama, aspek kesehatan yang dituju kepada ibu hamil dan menyusui, anak balita dari umur 0 sampai 6 tahun. Kedua adalah aspek pendidikan, dimana sasarannya adalah anak sekolah dari tingkat sekolah dasar sampai tingkat sekolah menengah atas. Ketiga adalah aspek kesejahteraan sosial, dengan sasaran para lansia dengan umur 70 tahun ke atas serta masyarakat penyandang disabilitas.

Penetapan pemilihan keluarga yang akan menjadi peserta PKH ini dilakukan dan ditetapkan secara terpusat oleh Direktur Jaminan Sosial Keluarga Harapan Kementerian Sosial RI melalui data kemiskinan tiap-tiap daerah. Data kemiskinan yang dijadikan pertimbangan penetapan peserta bersumber dari Data Terpadu Kesejahteraan Sosial (DTKS). Berdasarkan data tersebut kemudian Kementerian Sosial membuatkan undangan untuk diberikan kepada keluarga calon peserta melalui Koordinator PKH Kemensos di Kabupaten/Kota. Undangan tersebut masih dalam bentuk file yang kemudian oleh Administrator PKH undangan dicetak dan diberikan kepada masingmasing pendamping PKH. Setelah itu pendamping PKH melaporkan dan memberikan 
undangan ke Kecamatan dan kemudian melalui Kecamatan, undangan diserahkan kepada Perangkat Desa. Setelah undangan sampai di Desa, lalu Perangkat Desa bersama Pendamping PKH akan melakukan validasi data. Validasi data yang dilakukan oleh perangkat desa bersama pendamping desa berupa kegiatan meninjau langsung keadaan keluarga yang termasuk dalam data calon peserta PKH. Hal ini bertujuan untuk memastikan apakah calon peserta yang terdaftar tersebut memang memiliki kondisi miskin.

Pertimbangan pelaksanaan validasi yaitu berdasarkan kriteria kemiskinan yang dikeluarkan oleh Badan Pusat Statistik, yaitu ditinjau dari keadaan rumah dan pendapatan keluarga tersebut. Di Desa Kota Rantang, tim validasi melakukan pengecekan keadaan rumah calon peserta minimal dalam kondisi bukan milik pribadi (sewa), berlantaikan tanah, berdinding tepas, dan beratap seng. Kemudian calon peserta PKH juga akan dilihat besaran jumlah penghasilan minimal di bawah 1 juta rupiah. Selama proses validasi ini, apabila ditemukan keluarga yang ternyata tidak layak mendapatkan bantuan $\mathrm{PKH}$, maka dilakukan proses pengumpulan bukti-bukti berupa foto sebagai penguat validasi. Setelah pendamping bersama perangkat desa telah selesai melakukan pertinjauan terhadap kelayakan calon peserta, maka data validasi akan diserahkan kembali kepada Kementerian Sosial. Namun pun demikian, masih ada tahapan verifikasi oleh Kemterian Sosial terhadap data yang sudah divalidasi pendamping PKH. Artinya, jumlah calon peserta yang sudah tervalidasi belum tentu akan disetujui seluruhnya oleh Kementerian Sosial. Berdasarkan hasil verifikasi dapat terjadi dari $50 \mathrm{KK}$ yang divalidasi pendamping $\mathrm{PKH}$, hanya sekitar $30 \mathrm{KK}$ yang di verifikasi oleh Kementerian Sosial. Akhirnya verifikasi ini menjadi tahapan terakhir dalam proses penetapan peserta $\mathrm{PKH}$. Sehingga hasil verifikasi kemudian setiap peserta dibuatkan buku rekening. Untuk lebih jelasnya berikut gambaran skema penetapan peserta PKH di Desa Kota rantang.

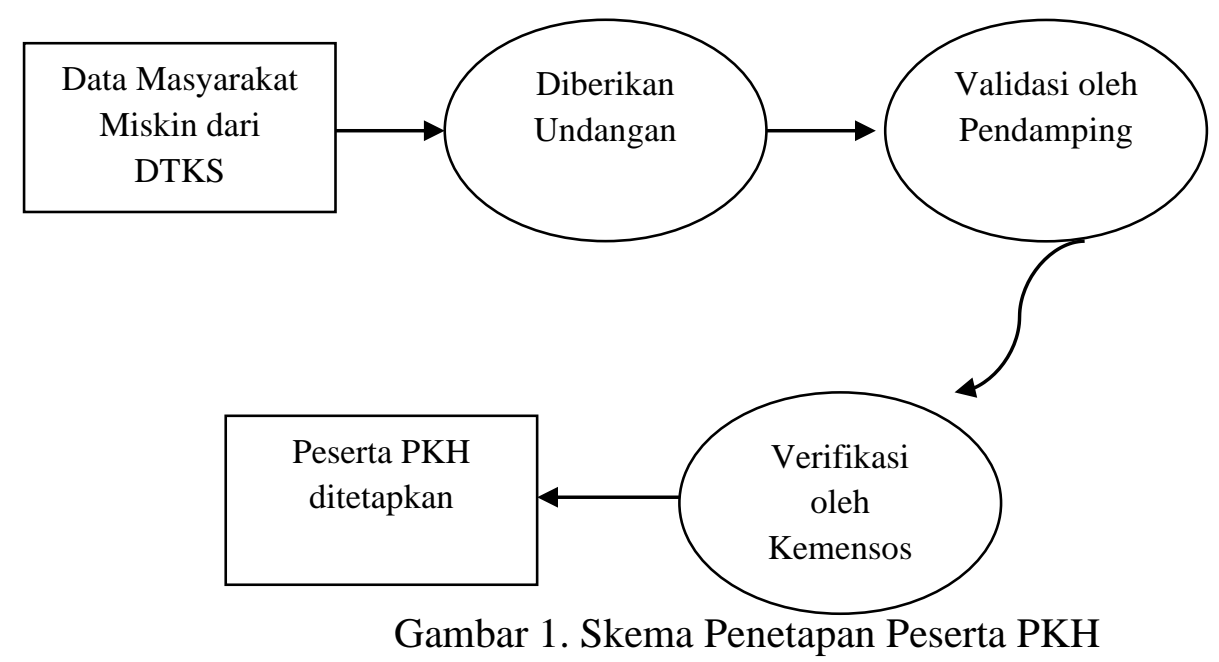




\section{Pelaksanaan Program Keluarga Harapan}

Pelaksanaan program keluarga harapan di Desa Kota Rantang Kecamatan Hamparan Perak ini telah dimulai sejak tahun 2015. Setelah peserta ditetapkan dan dibuatkan buku rekening, maka bantuan dana PKH didapatkan masyarakat sebanyak 4 (empat) kali dalam setahun, yaitu setiap bulan Januari, April, Juli, dan bulan Oktober. Namun, selama adanya situasi pandemic Covid-19, dana bantuan PKH diterima masyarakat setiap bulannya. Dana bantuan PKH ini bisa langusng diambil masyarakat melalui bank sesuai buku rekening yang dimiliki. Pada awal adanya PKH di desa ini, pendamping desa ataupun perangkat desa memiliki peran untuk mengawal masyarakat yang belum mengerti proses pengambilan dana bantuan. Akan tetapi seiring berjalnnya waktu, masyarakat sudah mulai terbiasa dan mengerti untuk mengambil sendiri.

Berdasarkan tahapan pencairan dana PKH yang terdiri atas empat bulan dalam setahun, tiap tahap ke-dua, ke-tiga, dan ke-empat selalu ada pemutakhiran. Pemutakhiran ini dilakukan oleh pendamping desa, dengan bantuan perangkat desa. Kegiatan pemutakhiran ini merupakan tinjuan ulang terhadap kondisi-kondisi masyarakat yang telah mendapatkan PKH. Tujuannya untuk memverifikasi status sosial keluarga, apakah ada perubahan status miskin menjadi tidak miskin, ataupun keadaan peserta yang sudah bercerai maupun meninggal dapat dilakukan penghentian penyaluran bantuan.

Selain peran dalam pemutakhiran, pendamping Desa Kota Rantang juga melakukan evaluasi terhadap setiap bulannya dalam pelaksanaan PKH baik pada aspek kesehatan, pendidikan maupun aspek kesejahteraan sosial. Setiap bulan pendamping melakukan pertemuan kepada seluruh peserta PKH untuk menilai apakah kewajiban setiap peserta telah dipenuhi. Pada aspek kesehatan, dilakukan pengecekan terhadap buku KIA (kesehatan Ibu dan Anak) untuk ibu hamil, serta buku KMS (Kartu Menuju Sehat) untuk balita. Hal ini bertujuan untuk melihat apakah ibu hamil rutin mengecek kesehatannya dan begitu juga dengan anak balita yang selalu diberi imunisasi serta pengecekan kesehatan secara rutin. Selama tahun 2020, ibu hamil dan anak balita di Kota Rantang selalu memeriksakan kesehatannya secara rutin, baik di posyandu maupun di puskesmas. Hal ini berarti kewajiban peserta ibu hamil dan anak balita telah dipenuhi sesuai dengan kebijakan Kemensos dalam buku pedoman pelaksanaan PKH tahun 2020.

Pada bidang pendidikan, pendamping desa melakukan evaluasi dengan meninjau sekolah-sekolah tempat anak peserta yang mendapatkan bantuan PKH. Baik dari tingkat sekolah dasar, sekolah menengah pertama, dan sekolah menengah atas, dilihat melalui kehadirannya. Selama tahun 2020 karena adanya pandemi covid-19, peserta anak sekolah di Desa Kota Rantang rata-rata sekitar 93\% telah hadir melalui kelas daring. Pada awal-awalnya mendapatkan kendala berupa tidak memiliki smartphone. Namun 
pada akhirnya, memakai milik orang tuanya. Hal ini mengindikasikan bahwa pada aspek pendidikan telah berjalan sesuai kebijakan Kemensos, dimana minimal tingkat partisipasi atau kehadiran anak sekolah adalah 85\%. Sedangkan evaluasi PKH pada aspek kesejahteraan sosial dilakukan dengan mengunjungi secara langsung para lansia dan penyandang disabilitas. Pendamping melakukan pengecekan kesehatan mereka. Para lansia dan penyandang disabilitas diwajibkan untuk memeriksakan kesehatan setiap bulannya dengan memberikan bukti berupa data cek up yang telah dilakukan.

\section{Kendala dalam Pelaksanaan Program Keluarga Harapan}

Setiap bulannya selalu diadakan pertemuan peserta PKH untuk dibina dan dibimbing agar masyarakat dapat meningkatkan kemampuan keluarganya. Hal ini dilakukan agar bantuan PKH tidak menjadi sumber pendapatan utama keluarga yang akan diterima seumur hidup. Tujuan daripada PKH itu sendiri menurut Kemensos sebenarnya adalah upaya pertolongan pemerintah agar masyarakat miskin mendapatkan modal awal dalam meningkatkan kesejahteraan keluarganya. Berdasarkan studi lapangan, didapatkan bahwa telah banyak peningkatan anak yang bersekolah di Desa Kota Rantang hingga akhirnya anak tersebut dapat lulus dan bekerja. Sehingga hal ini berdampak pada kesejahteraan keluarganya. Oleh karena itu, di Desa Kota Rantang sebenarnya sudah jarang ditemukan masyarakat yang benar benar miskin dengan keadaan rumah yang tidak berlantai, berdindingkan tepas.

Saat ini sudah banyak masyarakat desa Kota Rantang melakukan pembangunan rumah sebagai tempat tinggal yang layak. Rata-rata rumah di desa tersebut sudah berlantaikan keramik, dan semua rumah sudah berdindingkan batu. Sehingga sebenarnya, apabila ditinjau kemiskinan masyarakat Desa Kota Rantang sesuai faktor kemiskinan yang dilihat dari 4 hal yaitu: 1) rendahnya tingkat pendidikan; 2) rendahnya tingkat kesehatan dan gizi yang rendah menyebabkan rendahnya daya tahan fisik; 3) terbatasnya lapangan kerja; dan 4) kondisi keterisolasian yang berarti daerah terpencil atau terisolasi dari dunia perekonomian (Kartasasmita, 1996). Dilihat dari pandangan tersebut, maka sebenarnya masyarakat Desa Kota Rantang sudah tidak termasuk masyarakat miskin. Namun, apabila ditinjau dari pendapatan atau penghasilan kepala keluarga dibanding dengan jumlah anggota keluarga, rata-rata masih kurang. Karena sebagian besar masyarakat desa tersebut adalah petani. Apalagi selama adanya pandemi Covid-19, banyak masyarakat Desa Kota Rantang yang terdampak kehilangan pekerjaan. Sehingga mereka mendapatkan bantuan sosial dari pemerintah pusat.

Kendala yang terjadi selama pelaksanaan PKH terdapat dua hal, pertama yaitu sulitnya menjadwalkan pertemuan kelompok sebulan sekali. Hal ini terjadi karena kesibukan peserta dalam bekerja sehingga menyamakan waktu kosong. Terkadang dalam pertemuan yang dilakukan tidak dihadiri oleh seluruh peserta. Sehingga ini menjadi kesulitan pendamping untuk membimbing dan mengarahkan peserta $\mathrm{PKH}$. 
Kendala kedua yaitu terkait pencairan dana yang terkadang tidak merata kesemua peserta. Hal ini dapat terjadi karena kendala dari bank dan juga dapat terjadi karena perubahan status peserta yang tidak diketahui oleh peserta tersebut. Sehingga hal ini berdampak pada munculnya protes-protes ke kantor Desa Kota Rantang.

\section{KESIMPULAN}

Berdasarkan syarat miskin dengan kondisi kelayakan rumah, peserta PKH Desa Kota Rantang sebenarnya tidak layak karena telah membangun rumah yang layak. Akan tetapi berdasarkan jumlah penghasilan keluarga, peserta $\mathrm{PKH}$ layak mendapatkan bantuan PKH khususnya selama pandemi banyak masyarakat terdampak kehilangan pekerjaan. Namun demikian, telah banyak terjadi perubahan yaitu pengurangan jumlah KK yang mendapatkan bantuan PKH di Desa Kota Rantang karena dianggap tidak lagi masuk kepada kategori keluarga miskin.

Pelaksanaan Program Keluarga Harapan, baik pada aspek kesehatan, pendidikan maupun kesejahteraan sosial telah berjalan dengan baik. Karena setiap bulannya selalu diadakan pertemuan untuk upaya membimbing peningkatan kesejahteraan masyarakat, meskipun setiap pertemuan tidak dihadiri oleh seluruh peserta, namun dapat bergantian pada pertemuan berikutnya. Adanya bantuan PKH telah berdampak baik kepada masyarakat Desa Kota Rantang. Ibu hamil dapat menjaga kesehatan dan pertumbuhan anak balita dapat meningkat, begitupun dengan anak-anak yang dapat bersekolah hingga lulus dan mendapatkan pekerjaan. Beberapa keluarga tidak lagi menjadi peserta PKH karena dianggap sudah tidak layak. Namun demikian, dalam pemutusan status peserta PKH sebaiknya dilakukan dengan penyampaian hasil evaluasi kepada peserta yang bersangkutan sehingga mereka dapat mengetahui dan memahami. Dengan begitu, tidak akan terjadi lagi protes terhadap perangkat desa.

\section{DAFTAR PUSTAKA}

BPS. (2020). Profil Kemiskinan di Indonesia Maret 2020. In Berita Resmi Statistik.

Dulkiah, M., Sari, A. L., \& Irwandi, I. (2018). The Impact of Conditional Cash Transfer (CCT) to Socio-Economic of Poor Families; A Case Study. Jurnal Ilmu Sosial Mamangan. https://doi.org/10.22202/mamangan.2580

Ekardo, A., Firdaus, F., \& Elfemi, N. (2014). Efektifitas Program Keluarga Harapan (PKH) Dalam Upaya Pengentasan Kemiskinan di Nagari Lagan Hilir, Kab. Pesisir Selatan. Jurnal Ilmu Sosial Mamangan.

Iskandar. (2009). Metodologi Penelitian Pendidikan dan Sosial. In Jakarta: Gaung Persada Press.

Kariono, A. C. (2011). Profesionalisme Aparatur Birokrasi(Studi pada Dinas Dinas Kependudukan, Keluarga Berencana dan Catatan Sipil Kabupaten Labuhan Batu). 
Juni.

Kartasasmita, G. (1996). Pembangunan untuk Rakyat: Memadukan Pertumbuhan dan Pemerataan. Economic Development-Indonesia; Economic Policy; Economic Conditions-1945.

Larasati, L., Muda, I., Batubara, B. M., \& Suharyanto, A. (2019). Peranan Dinas Pengendalian Penduduk dan Keluarga Berencana dalam Pengendalian Pertumbuhan Penduduk. PERSPEKTIF. https://doi.org/10.31289/perspektif.v7i1.2521

Lexy J. Moleong, D. M. A. (2000). Metodologi Penelitian Kualitatif. In PT. Remaja Rosda Karya.

Miles, M. B., Huberman, A. M., \& Saldana, J. (2014). Qualitative Data Analysis: A Methods Sourcebook. Third Edition. In The SAGE Handbook of Applied Social Research Methods. 